\title{
Surface Characteristics of Leafy Vegetables and Their Effects on Salmonella Attachment
}

\author{
Chanthima Phungamngoen ${ }^{1, *}$ and Sriwiang Rittisak ${ }^{2}$ \\ ${ }^{1}$ Department of Agro industry and management, Faculty of agro industry, King Mongkut's University of Technology North Bangkok, \\ Thailand \\ ${ }^{2}$ Department of Innovation and product development technology, Faculty of agro industry, King Mongkut's University of Technology \\ North Bangkok, Thailand
}

\begin{abstract}
Leafy vegetables exhibit non-uniform surfaces and are structured with interconnected networks of veinlets or wrinkle characteristics, making the quantification of the changes rather difficult. In this study, attempt was made to quantify the surface topographical features of leafy vegetable. Image analysis was used to determine the characteristic of vegetable surface. In term of surface area $(A)$, the results were compared with those correlated with the data obtained by a conventional measurement method. It was also performed to determine fractal dimension (FD) and roughness value $(R)$ to describe the behavior of bacteria attached on the vegetable surface. The results showed that different leafy vegetable (basil, lemon basil, peppermint and cabbage) did not have a significant effect on Salmonella attached on surface. Dorsal side (upper side) of leaves exhibited higher $R$ and lower FD than ventral side (lower side). It led to number of Salmonella attached on upper side of leaves showed higher than their lower side. From Pearson's correlation, FD could relate well with the number of Salmonella attached on surface of vegetable. FD showed the highest correlation (-0.78-(-0.97)) follow by $A(0.77-0.86)$ and $R(0.61-0.87)$, respectively. Therefore, the parameters from image analysis were found to be good indicator to describe the physical characteristics of leafy vegetable.
\end{abstract}

\section{Introduction}

Image analysis has long proven to be a useful mean for inspection and grading food and agricultural products. Recently, the uses of image analysis technique for quality evaluation of food products have been widely developed and recommended for the evaluation of textural changes of being processed foods [1-3]. Base on image analysis techniques, fractal analysis is one of popular techniques to monitor microstructural changes of food product during process because it has proved to be capable of characterizing the degree of irregularity of products [4-6]. For example, Wright \& Marangoni [7] applied fractal analysis to describe the microstructure of fat particles in milk during thermal processing. By using this technique, the size of fat particles could be determined successfully. Fractal dimension was noted to be capable of monitoring the microstructural changes of the samples and can serve as a generalized structure-quality indicator of the tested products undergoing drying $[5,8]$.

Using image analysis to monitor the changes of vegetable surfaces is needed because the developing of surface change during drying would trap and protect Salmonella, a pathogenic bacterium of serious concern to public health, from direct exposure to heat [9]. Hawaree et. al. [2] developed an image analysis technique in terms of the relative roughness factor $(R)$ to monitor the changes of vegetable surfaces during drying on the Salmonella attachment ability. It was observed that $R$ value could be well monitored surface characteristic changes during drying.

Although, there are some previous works on the characterization of food texture and surface characteristics by image analysis [1-8], there is so far no study that attempts to describe the surface characteristics of different leafy vegetables. It is important to note that vegetable surfaces showed non-uniform pattern of venation. They are connected with networks of wrinkle characteristics. This making the quantification of the surface difficult. In this study, attempt was made to quantify the changes of the surface topographical features of vegetables. This value should be able to correlate with an attachment ability of microbiology on vegetable surface. Salmonella was used as the tested pathogenic bacteria as this microorganism is frequently reported to be associated with raw and ready-to-eat fruits and vegetables [10].

\section{Material and methods}

\subsection{Sample preparation}

Selected vegetables (basil, lemon basil, peppermint and cabbage) were obtained from a local market. The edible 
leaves of vegetables were washed with tap water for $2 \mathrm{~min}$. In the case of cabbage, it was cut into the sizes of $20 \times 20 \mathrm{~mm}$.

\subsection{Bacterial cell culture and preparation}

Working cultures ( Salmonella Typhimurium TISTR 1469) were prepared by inoculating a loopful of a stock culture into $100 \mathrm{~mL}$ of Tryptone Soy Broth (TSB, Oxoid, Basingstoke, U.K.) and was shaken in a shaker incubator (New Brunswick Scientific, model Innova 4230, Edison, NJ) at $200 \mathrm{rpm}$ and at $37^{\circ} \mathrm{C}$ for $18 \mathrm{~h}$ to obtain the bacterial cells in stationary phase. The viable count contained in working culture was approximately $8 \log \mathrm{CFU} / \mathrm{mL}$.

\subsection{Inoculation and enumeration of Salmonella}

Background microorganisms were reduced followed the method of Phungamngoen et. al. [10] by soaking leaves into $70 \%$ ethanol for $30 \mathrm{~s}$. Ten grams of vegetables were soaked in $100 \mathrm{~mL}$ of the culture suspension for $1 \mathrm{~min}$; the flask was shaken at $200 \mathrm{rpm}$ in a shaker incubator (New Brunswick Scientific, model Innova 4230, Edison, NJ). The inoculated samples were air dried in a laminar flow hood (Clean, model V4, Bangkok, Thailand) for $30 \mathrm{~min}$ and stored at $4^{\circ} \mathrm{C}$ for $24 \mathrm{~h}$. Samples were then diluted in $50 \mathrm{~mL}$ of $0.1 \%$ peptone water and homogenized in a stomacher (Seward, model 400 Circulator, UK) for $2 \mathrm{~min}$. Salmonella numbers were enumerated by spread plating $0.1 \mathrm{~mL}$ of diluted sample onto TSA plates after an incubation time of $48 \mathrm{~h}$ at $37^{\circ} \mathrm{C}$.

\subsection{Image Processing}

Photos of the selected vegetables were taken by digital camera (lens AF-S NIKON 18-140 mm, camera model D5500, Nikon, Japan). The light source was fixed to the control box $(20 \times 20 \times 20 \mathrm{~cm})$. Ten samples $(1$ unit $=10$ leaves) were evaluated for each vegetable surface (three replication for sample $=3 \times 10$ leaves). The samples were placed flat under the lens of the camera. The original image was saved in Bitmap image file format with size of 7.61 MB $(1600 \times 1248$ pixels $)$. Image processing was performed using ImageJ version $1.37 \mathrm{c}$ (Natl. Inst. of Health, Bethesda, MD) to determine surface area $(A)$, Roughness value $(R)$ and Fractal dimension (FD).

\subsubsection{Surface area $(A)$}

Samples were evaluated surface area $(A)$ by Simpson's rule (a conventional measurement method). The equation showed as follow:

$$
\text { area }=\frac{1}{3} a\left(y_{0}+4 y_{1}+2 y_{2}+\ldots+2 y_{n-2}+4 y_{n-1}+y_{n}\right)
$$

where $n$ is an even.

$a$ is dividing the leaf space into even numbers with equal segments of width. $y_{0}, y_{1}, y_{2}, \ldots, y_{n}$ are the height of each dividing line.
Each image was filtered by a rotationally symmetric Gaussian low-pass filter to diminish noise. The image was then transformed from gray scale (8-bit) to a black and white format before a calculation of the surface area $(A)$ was performed. An Otsu's method was used as a suitable thresholding.

\subsubsection{Roughness value $(R)$}

Image processing was followed the method of evaluation surface area $(A)$. The roughness value can be calculated by different number of pixels from binary image (1) and binary image (2). The scheme of test surface vegetable for evaluates roughness value $(R)$ are showed in Fig. 1.

Color image $(1600 \times 1248$ pixels $)$

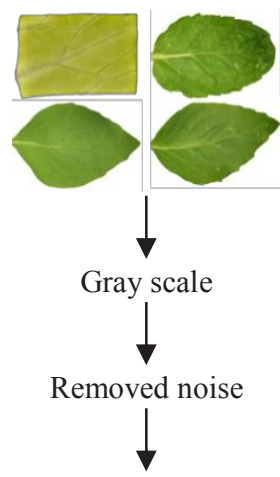

Thresholding by Otsu's method (190-200); Binary image (1)

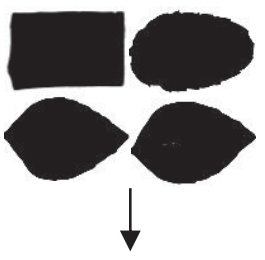

Thresholding by suitable threshold (130-140); Binary image (2)
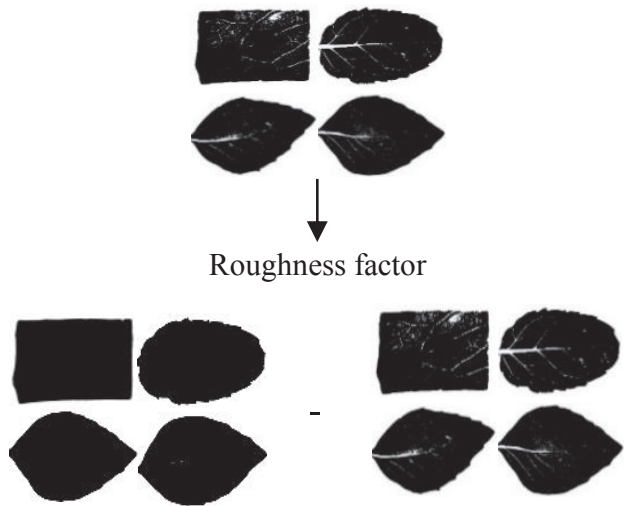

Fig. 1. Scheme of test surface vegetable for evaluates roughness value $(R)$.

\subsubsection{Fractal dimension (FD)}

An original bitmap image was then cropped into the sizes of $720 \times 720$ pixels. Image processing was followed the method of evaluation surface area $(A)$. The fractal 
dimension of a black and white image (binary image) was calculated using the box counting method [11].

\subsection{Pearson's correlation coefficient}

The correlations between FD, $A, R$, and number of Salmonella were determined by the Pearson's correlation coefficient. Pearson's correlation coefficient is calculated by Equation (2)

$$
r=\frac{\sum X Y-\frac{\sum X \sum Y}{N}}{\sqrt{\sum X^{2}-\frac{\left(\sum X\right)^{2}}{N}\left(\sum Y^{2}-\frac{\left(\sum Y\right)^{2}}{N}\right)}}
$$

where $X, Y$ and $N$ represent the data of variables $X, Y$ and the number of data $X$ and $Y$, respectively.

\subsection{Experimental design and statistical analysis}

The experiments were conducted at four different leafy vegetables and two sides of each vegetable. A 2-factor factorial design was used to schedule the experiments. The effects of the different leafy vegetables were determined by univariate full-factorial analysis of variance (ANOVA) using MINITAB $^{\circledR}$ software (version 14, State College, PA).

\section{Results and discussion}

\subsection{Salmonella attached on vegetable surface}

Initial numbers of Salmonella on leafy vegetables (basil, lemon basil and peppermint) were not significant difference (data were not shown). Table 1 shows the number of Salmonella on surface vegetable. Salmonella, in the case of cabbage showed significant difference with others $(p<0.05)$. It was observed that Salmonella on peppermint were higher than basil, lemon basil and cabbage, respectively. This is because bacterial cells likely distribute on smooth surface and preferably attach around stomata and rough surfaces, such as veins of leafy vegetables and netted rinds surface of some fruits $[2,12]$.

Table 1. Salmonella on surface vegetables.

\begin{tabular}{lccc}
\hline \multirow{2}{*}{ Vegetable } & \multicolumn{3}{c}{ Salmonella $(\log$ CFU/m } \\
\cline { 2 - 4 } & Whole leaf & Lower side & Upper side \\
\hline Basil & $10.95 \pm 0.01^{\mathrm{aA}}$ & $10.62 \pm 0.01^{\mathrm{bC}}$ & $10.64 \pm 0.01^{\mathrm{bB}}$ \\
Lemon basil & $10.91 \pm 0.01^{\mathrm{bA}}$ & $10.59 \pm 0.03^{\mathrm{cBC}}$ & $10.61 \pm 0.01^{\mathrm{cB}}$ \\
Peppermint & $10.98 \pm 0.01^{\mathrm{aA}}$ & $10.68 \pm 0.02^{\mathrm{aC}}$ & $10.71 \pm 0.01^{\mathrm{aB}}$ \\
Cabbage & $10.86 \pm 0.04^{\mathrm{cA}}$ & $10.55 \pm 0.02^{\mathrm{dB}}$ & $10.54 \pm 0.02^{\mathrm{dB}}$ \\
\hline
\end{tabular}

Values in the same column with different superscripts mean that the values are significantly different $(p<0.05)$.

Same capital letters in the same row indicate that values are not significantly different $(p \geq 0.05)$.

Dorsal side (upper side) of leaves exhibited rough surfaces and clear veins of leafy than ventral side (lower side). It led to number of Salmonella attached on upper side of leaves showed higher than their lower side.

\subsection{Surface characteristics of vegetables}

Table 2 shows color image of different vegetable. A clear cell periphery and the network of venation showed in the surface of fresh vegetable. Different types of vegetable showed different pattern of venation. Upper side of leaves had clearly the network of venation more than those lower side.

Table 2. Color images of selected vegetable.

\begin{tabular}{|l|l|l|}
\hline \multicolumn{1}{|c|}{ Vegetable } & Lower side & Upper side \\
\hline Basil & \\
\hline Lemon basil & \\
\hline Peppermint & & \\
\hline Cabbage & & \\
\hline
\end{tabular}

Surface characteristic of leafy vegetable showed rough surface of a pattern of venation. It can promote the entrapment and attachment of bacteria. The results agreed well with Wang et al. [13]. They studied the effect of surface roughness on the retention and the removal of Escherichia coli $\mathrm{O} 157: \mathrm{H7}$ on surfaces of golden delicious apples, navel oranges, avocadoes, and cantaloupes. It was found that the bacterial adhesion rate increased with an increase in surface roughness. This could be due to an increase in surface area for bacterial adhesion.

\subsubsection{Surface area $(A)$}

Table 3 showed comparison of vegetable surface area between conventional method (Simpson's rule) and image analysis. It was observed that values by different methods were not significant difference. Therefore, image analysis could be a good method to evaluate characteristics of leafy vegetables.

Table 3. Surface area of vegetables.

\begin{tabular}{llcc}
\hline \multirow{2}{*}{ Vegetable } & Simpson's & \multicolumn{2}{c}{ Image analysis $\left.\mathbf{( c m}^{\mathbf{2}}\right)$} \\
\cline { 4 - 5 } & rule $\left(\mathbf{c m}^{\mathbf{2}}\right)$ & Lower side & Upper side \\
\hline Basil $^{\text {ns }}$ & $5.48 \pm 1.21^{\mathrm{b}}$ & $5.95 \pm 1.20^{\mathrm{b}}$ & $6.21 \pm 1.17^{\mathrm{a}}$ \\
Lemon basil $^{\mathrm{ns}}$ & $6.06 \pm 1.04^{\mathrm{a}}$ & $6.28 \pm 1.42^{\mathrm{ab}}$ & $6.26 \pm 1.20^{\mathrm{a}}$ \\
Peppermint $^{\mathrm{ns}}$ & $6.31 \pm 0.75^{\mathrm{a}}$ & $6.73 \pm 0.88^{\mathrm{a}}$ & $6.72 \pm 0.83^{\mathrm{a}}$ \\
Cabbage $^{\mathrm{ns}}$ & $4.12 \pm 0.11^{\mathrm{c}}$ & $4.13 \pm 0.09^{\mathrm{c}}$ & $4.15 \pm 0.11^{\mathrm{b}}$ \\
\hline
\end{tabular}

Values in the same column with different superscripts mean that the values are significantly different $(p<0.05)$.

\subsubsection{Roughness value $(R)$}

Table 4 showed roughness factor performed by image processing. As mentioned earlier, color images taken for the vegetable surfaces was converted into the binary images using an appropriate thresholding. The areas appearing as black color indicated a background or a smooth surface, while the white areas represented the 
rough surfaces. A larger area of white color was clearly observed when the sample had clear vein, leading to higher $R$ of the samples. The highest value was found in the case of peppermint follows by lemon basil, basil and cabbage, respectively. It indicated that peppermint had a rough surface than others. Upper side of leaves exhibited higher $R$ than lower side.

Table 4. Roughness factor $(R)$ of vegetables.

\begin{tabular}{lll}
\hline \multicolumn{1}{c}{ Vegetable } & Lower side & Upper side \\
\hline Basil & $0.17 \pm 0.10^{\mathrm{aB}}$ & $0.33 \pm 0.21^{\mathrm{aA}}$ \\
Lemon basil & $0.20 \pm 0.09^{\mathrm{aB}}$ & $0.32 \pm 0.11^{\mathrm{aA}}$ \\
Peppermint & $0.21 \pm 0.10^{\mathrm{aB}}$ & $0.34 \pm 0.10^{\mathrm{aA}}$ \\
Cabbage & $0.10 \pm 0.06^{\mathrm{bA}}$ & $0.11 \pm 0.06^{\mathrm{bA}}$ \\
\hline
\end{tabular}

Values in the same column with different superscripts mean that the values are significantly different $(p<0.05)$.

Same capital letters in the same row indicate that values are not significantly different $(p \geq 0.05)$.

\subsubsection{Fractal dimension (FD)}

Fractal dimension spans in Euclidean dimension that it indicates the degree to which an image or object outline deviates from smoothness and regularity [14]. Table 5 showed fractal dimension (FD) of vegetables.

Table 5. Fractal dimension (FD) of vegetables.

\begin{tabular}{lll}
\hline \multicolumn{1}{c}{ Vegetable } & Lower side & Upper side \\
\hline Basil & $1.46 \pm 0.07^{\mathrm{bA}}$ & $1.37 \pm 0.03^{\mathrm{bB}}$ \\
Lemon basil & $1.28 \pm 0.07^{\mathrm{cA}}$ & $1.22 \pm 0.02^{\mathrm{cB}}$ \\
Peppermint & $1.24 \pm 0.04^{\mathrm{cA}}$ & $1.19 \pm 0.01^{\mathrm{dB}}$ \\
Cabbage & $1.59 \pm 0.06^{\mathrm{aA}}$ & $1.57 \pm 0.02^{\mathrm{aA}}$ \\
\hline
\end{tabular}

Values in the same column with different superscripts mean that the values are significantly different $(p<0.05)$.

Same capital letters in the same row indicate that values are not significantly different $(p \geq 0.05)$.
The lower values indicated that peppermint surface showed higher irregularity with more pronounce in the appearance of roughness surface. Results of fractal dimension of vegetable were consistent with the reports of Quevedo et al. [11]. Those authors applied fractal image texture analysis to describe the texture and microstructure of various foods such as pumpkin, potato, carrot, apple and banana. Higher values of fractal dimension represented more complex or rougher surfaces. Fractal dimension was found to correlate well with visual characteristics and roughness of standard material (sandpaper). As the results mentioned earlier, FD could be used as the indicator to monitor surface characteristics of vegetables.

\subsection{Correlation}

An attempt has been made in this work to investigate whether there was any effect of food surface characteristics on the Salmonella attached on surface. The relationship between surface characteristics factors and numbers of Salmonella were shown in Table 6. Pearson's correlation coefficient $(r)$ is the degree of the linear relationship measurement between two factors and the $r$ value may take on any values between plus $(+)$ and minus ( - ) one; $+/$ - sign representing the direction of the relationship. The high correlations were obtained with Pearson's correlation between \pm 0.75 to \pm 0.99 .

A good correlation was found with the high Pearson's correlation indicating that the rough surface area significantly affected Salmonella on surface vegetables. The linear relationship was observed. It was seen that FD showed the highest correlation $(-0.78-(-0.97))$ following by $A(0.77-0.86)$ and $R(0.61-0.87)$, respectively. It means that $A$ and $R$ increased with increasing Salmonella on surface of vegetables.

Table 6. Correlation surface characteristics parameter with different vegetable and Salmonella attached on surface vegetables.

\begin{tabular}{|c|c|c|c|c|c|c|c|c|c|c|c|c|}
\hline Factor & $\begin{array}{c}\text { Salmonella } \\
\text { whole leaf }\end{array}$ & $\begin{array}{l}\text { Salmonella } \\
\text { lower side }\end{array}$ & $\begin{array}{c}\text { Salmonella } \\
\text { upper side }\end{array}$ & $\begin{array}{c}A \\
\text { whole } \\
\text { leaf }\end{array}$ & $\begin{array}{c}A \\
\text { lower } \\
\text { side }\end{array}$ & $\begin{array}{c}A \\
\text { upper } \\
\text { side }\end{array}$ & $\begin{array}{c}R \\
\text { whole } \\
\text { leaf }\end{array}$ & $\begin{array}{c}R \\
\text { lower } \\
\text { side }\end{array}$ & $\begin{array}{c}R \\
\text { upper } \\
\text { side }\end{array}$ & $\begin{array}{c}\text { FD } \\
\text { whole } \\
\text { leaf }\end{array}$ & $\begin{array}{c}\text { FD } \\
\text { lower } \\
\text { side }\end{array}$ & $\begin{array}{c}\text { FD } \\
\text { upper } \\
\text { side }\end{array}$ \\
\hline $\begin{array}{l}\text { Salmonella } \\
\text { whole leaf }\end{array}$ & 1.00 & 0.98 & 0.99 & 0.83 & 0.77 & 0.81 & 0.87 & 0.66 & 0.80 & -0.97 & -0.83 & -0.93 \\
\hline $\begin{array}{l}\text { Salmonella } \\
\text { lower side }\end{array}$ & 0.98 & 1.00 & 0.99 & 0.83 & 0.77 & 0.82 & 0.82 & 0.61 & 0.75 & -0.87 & -0.78 & -0.91 \\
\hline $\begin{array}{l}\text { Salmonella } \\
\text { upper side }\end{array}$ & 0.99 & 0.99 & 1.00 & 0.86 & 0.80 & 0.84 & 0.86 & 0.62 & 0.80 & -0.89 & -0.80 & -0.92 \\
\hline$A$ whole leaf & 0.83 & 0.83 & 0.86 & 1.00 & 0.95 & 0.95 & 0.75 & 0.29 & 0.86 & -0.61 & -0.52 & -0.66 \\
\hline$A$ lower side & 0.77 & 0.77 & 0.80 & 0.95 & 1.00 & 0.81 & 0.63 & 0.21 & 0.74 & -0.54 & -0.45 & -0.59 \\
\hline$A$ upper side & 0.81 & 0.82 & 0.84 & 0.95 & 0.81 & 1.00 & 0.79 & 0.35 & 0.88 & -0.63 & -0.54 & -0.68 \\
\hline$R$ whole leaf & 0.87 & 0.82 & 0.86 & 0.75 & 0.63 & 0.79 & 1.00 & 0.76 & 0.91 & -0.81 & -0.79 & -0.80 \\
\hline$R$ lower side & 0.66 & 0.61 & 0.62 & 0.29 & 0.21 & 0.35 & 0.76 & 1.00 & 0.43 & -0.72 & -0.69 & -0.72 \\
\hline$R$ upper side & 0.80 & 0.75 & 0.80 & 0.86 & 0.74 & 0.88 & 0.91 & 0.43 & 1.00 & -0.68 & -0.66 & -0.66 \\
\hline $\begin{array}{l}\text { FD whole } \\
\text { leaf }\end{array}$ & -0.91 & -0.87 & -0.89 & -0.61 & -0.54 & -0.63 & -0.81 & -0.72 & -0.68 & 1.00 & 0.97 & 0.97 \\
\hline $\begin{array}{l}\text { FD lower } \\
\text { side }\end{array}$ & -0.83 & -0.78 & -0.80 & -0.52 & -0.45 & -0.54 & -0.79 & -0.69 & -0.66 & 0.97 & 1.00 & 0.89 \\
\hline $\begin{array}{l}\text { FD upper } \\
\text { side }\end{array}$ & -0.93 & -0.91 & -0.92 & -0.66 & -0.59 & -0.68 & -0.80 & -0.72 & -0.66 & 0.97 & 0.89 & 1.00 \\
\hline
\end{tabular}


It was found that the bacterial adhesion rate increased with an increase in surface roughness. Surface topographical features of vegetables can help the attachment of Salmonella. This is because bacterial cells likely distribute on smooth surface and especially attach to rough surfaces such as stomata of leafy vegetables and netted rinds surface of vegetable $[9,10]$. This could be due to an increase in surface area for bacterial adhesion. On the other hand, FD decreased with increasing Salmonella. An increase in the cellular contraction, as a result of the clearly pattern of veins, was represented by higher $R$ and lower FD values.

\section{Conclusion}

The effects of surface characteristics of different vegetable on Salmonella attached on surface were investigated. The results showed that different surface characteristics could affect the number of Salmonella. Rough surface was found Salmonella more than smooth surface as shown in the case of peppermint, lemon basil, basil and cabbage, respectively. Surface area from image analysis were not significant difference with the value from Simpson's rule. The correlation between surface characteristics ( $R$ and FD) and Salmonella were high demonstrated that the parameters from image analysis were found to be good indicators to describe the physical characteristics of leafy vegetable and to represent number of contaminated bacteria on food surface.

The authors express their sincere appreciation to the King Mongkut's University of Technology North Bangkok for financially supporting the study in the form of the General Researcher Grant. Author Phungamngoen thanks the Ambassador of France, through its Junior Research Fellowship Program for supporting her study in Toulouse, France.

\section{References}

1. L. Fernandez, C. Castillero, J.M. Aguilera, J Food Eng. 67, 185-193 (2005)

2. N. Hawaree, N. Chiewchan, S. Devahastin, J Food Sci. 74, E16-E22 (2009)

3. N. Chiewchan, C. Praphraiphetch, S. Devahastin, J Food Eng. 101, 41-48 (2010)

4. R. Quevedo, J. M. Aguilera, J Food Eng. 65, 1-7 (2004)

5. S. Kerdpiboon, S. Devahastin, W.L. Kerr, J Food Eng. 83, 570-580 (2007)

6. N.A. Valous, F. Medoza, W.D. Sun, P. Allen, Food Res Int. 42, 353-362 (2009)

7. A.J. Wright A.G. Marangoni, J Food Sci. 68, 182-186 (2003)

8. S. Sansiribhan, S. Devahastin, S. Soponronnarit, J Food Eng. 109, 148-154 (2012)

9. N. Chiewchan, P. Morakotjinda, Dry Tech. 27, 955961 (2009)

10. C. Phungamngoen, N. Chiewchan, S. Devahastin, Int J Food Mic. 147, 127-133 (2011)

11. R. Quevedo, L.G. Carlos, J.M. Aguilera, L. Cadoche, J Food Eng. 53, 361-371 (2002)

12. T.C. Ells, L.T. Hansen, Int J Food Mic. 111, 34-42 (2006)

13. H. Wang, H. Feng, W. Liang, Y. Luo, V. Malyarchuk, J Food Sci. 74, E8-E15 (2009)

14. A.H. Barrett, M. Peleg, LWT-Food Sci Tech. 28, 553-563 (1995) 